feet from the ground, where the tree had partially broken off in a previous storm. The upper part of the tree, supported by nearby spruce, had not completely broken away, but was angulated off at nearly a right angle, partially roofing the cavity of the stub which was open at one side.

The two young owls, about halfgrown and still downy, were banded. Bill Richards attempted a photograph (with fair success, considering that it was nearly 9 p.m. and that he was using kodachrome film in the deep woods without a flash attachment).

As an anticlimax, we visited a Great Horned Owl nest in a spruce about a quarter-mile distant. After I climbed up fifty feet, both young owls flew just before I reached the nest. The weaker flier of the two landed in a nearby tree. Anton climbed several trees in succession, the owl losing altitude with each flight until finally we were able to band him.

Mrs. Steve Waycheshen served us supper when we got back to the farm after dark. We were tired but very happy when we arrived back in Saskatoon at 3 a.m.

The Barred Owl was first added to the Saskatchewan list in 1959 (Houston, Blue Jay, 17:94). We have the
Waycheshens to thank for three of the six records, including the Klogei Lake bird which I banded on January 2, 1960 (Blue Jay, 18:105). This is the first nesting record for the province and it would be interesting to know whether the adult banded two winters before was one of the parents at the nest.

Russell Robertson is sure the Barred Owls occasionally nest in the Saskatchewan River lowlands near Cumberland House. Their range apparently extends south through the Porcupine Forest Reserve and, since there are records for Alberta and Manitoba, it probably occurs sparingly in the mixed forest right across the province. Support for this latter possibility is given by the comments of the Indian foreman of the firefighting crew. He came from Big River and before the Waycheshens had located the source of the strange noise, he correctly identified the strange distinctive "hoo, hoo, hoo, hoo-aw" as belonging to " a different and uncommon kind of owl." Two years ago Dr. A. E. Allin of Fort William prophesied that we would soon find a Barred Owl nest in Saskatchewan, and advised me to look in the tops of black poplar stubs. Members are advised to listen 'for the Barred Owl call, and watch for further Saskatchewan nests.

\title{
BANK SWALLOWS NESTING IN GRAVEL STOCKPILE NEAR CANORA
}

by Larry Morgotch, Yorkton

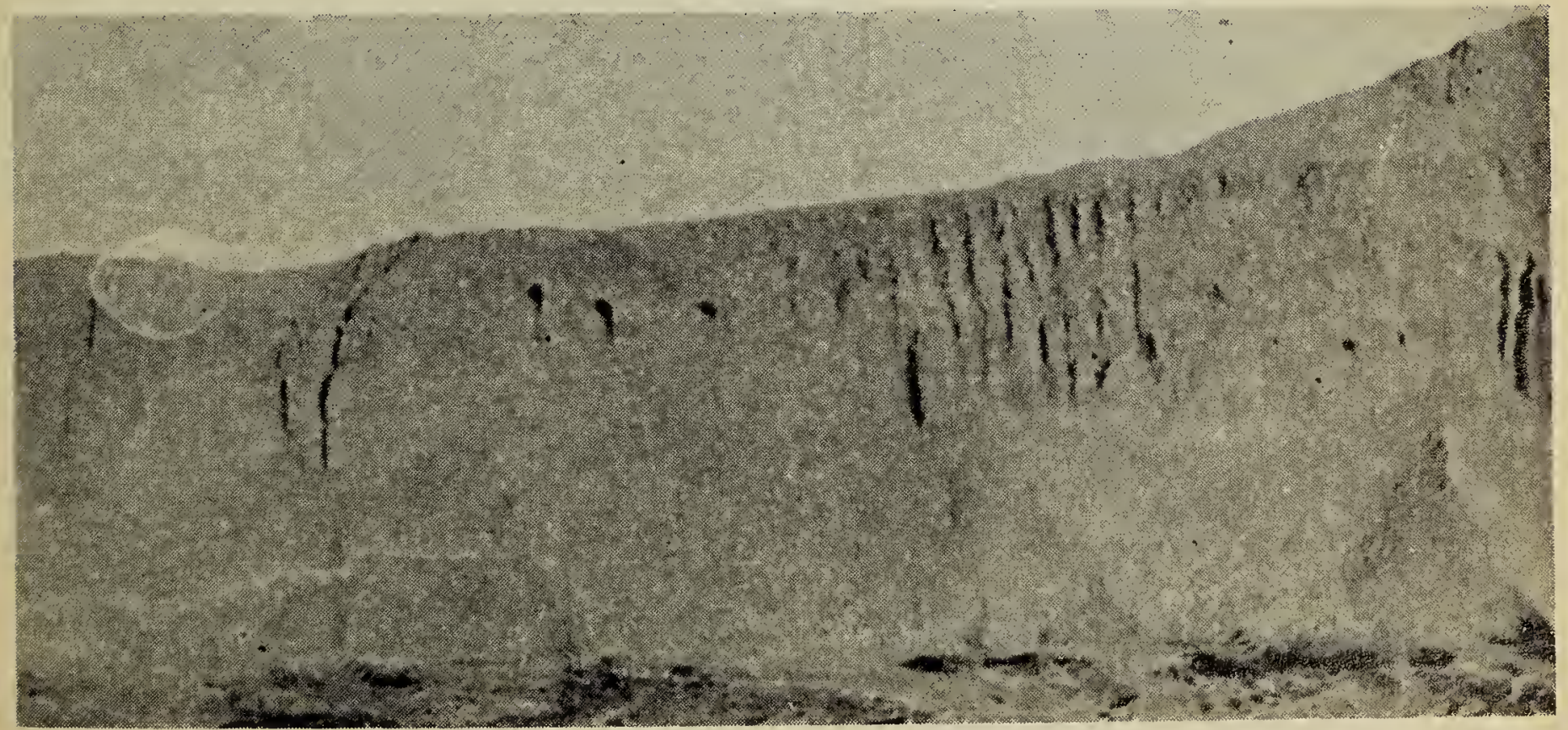

The photo show's a gravel stockpile eleven miles north of Canora, Sask. It has been undisturbed for dug without the wa'l collapsing. Bank Swallows' nests car also be found in sand dunes at Good Spirit Lake where the fine sand is well packed and tree roots help to keep it from caving in. 